\title{
Exploiting the mitochondrial unfolded protein response for cancer therapy in mice and human cells
}

\author{
Markus D. Siegelin, ${ }^{1}$ Takehiko Dohi, ${ }^{1,2}$ Christopher M. Raskett, ${ }^{3}$ Gregory M. Orlowski, ${ }^{3}$ \\ Christine M. Powers, ${ }^{3}$ Candace A. Gilbert, ${ }^{4}$ Alonzo H. Ross, ${ }^{4}$ Janet Plescia, ${ }^{3}$ and Dario C. Altieri ${ }^{1,2}$ \\ ${ }^{1}$ Prostate Cancer Discovery and Development Program and ${ }^{2}$ The Wistar Institute Cancer Center, Philadelphia, Pennsylvania, USA. \\ ${ }^{3}$ Department of Cancer Biology and ${ }^{4}$ Department of Biochemistry and Molecular Pharmacology, \\ University of Massachusetts Medical School, Worcester, Massachusetts, USA.
}

\begin{abstract}
Fine tuning of the protein folding environment in subcellular organelles, such as mitochondria, is important for adaptive homeostasis and may participate in human diseases, but the regulators of this process are still largely elusive. Here, we have shown that selective targeting of heat shock protein-90 (Hsp90) chaperones in mitochondria of human tumor cells triggered compensatory autophagy and an organelle unfolded protein response (UPR) centered on upregulation of CCAAT enhancer binding protein (C/EBP) transcription factors. In turn, this transcriptional UPR repressed NF- $\kappa B-$ dependent gene expression, enhanced tumor cell apoptosis initiated by death receptor ligation, and inhibited intracranial glioblastoma growth in mice without detectable toxicity. These data reveal what we believe to be a novel role of $\mathrm{Hsp} 90$ chaperones in the regulation of the protein-folding environment in mitochondria of tumor cells. Disabling this general adaptive pathway could potentially be used in treatment of genetically heterogeneous human tumors.
\end{abstract}

\section{Introduction}

Cells use sensor pathways compartmentalized in subcellular organelles to recognize stress conditions (1), including aberrant protein folding (2), and in response activate gene expression programs aimed at maintaining cell survival and restoring homeostasis. These compensatory responses are important in cancer (3), conferring adaptation to unfavorable milieus (4), and new malignant traits in vivo (5), raising the prospect that interfering with organelle unfolded protein response (UPR) may be beneficial for cancer therapy (6). Much of our knowledge regarding organelle UPR signaling comes from studies of the ER stress response machinery (7). In contrast, a potential role of mitochondria in UPR pathway(s), especially in cancer, is far less defined (8), and physiologic regulators of this pathway have not been clearly defined $(9,10)$.

Potential modulators of a mitochondria-selective UPR may include molecular chaperones of the heat shock protein-90 (Hsp90) family (11). Consistent with their broad distribution to various subcellular compartments (12), Hsp90 molecules, including Hsp90 and its related ATPase-directed chaperone, TNF receptor-associated protein-1 (TRAP-1), have been shown to localize to mitochondria, especially of tumor cells (13), where they antagonize cyclophilin D-dependent (CypD-dependent) organelle permeability transition (14). This cytoprotective pathway is universally exploited in cancer in vivo (13) and may predict aggressive disease, but whether mitochondrial Hsp90s function in broader signaling networks of organelle homeostasis, specifically in tumor cells, has not been examined.

In this study, we investigated a role of mitochondrial Hsp90s in the regulation of organelle-compartmentalized protein fold-

Authorship note: Markus D. Siegelin and Takehiko Dohi contributed equally to this work.

Conflict of interest: The authors have declared that no conflict of interest exists. Citation for this article: J Clin Invest. 2011;121(4):1349-1360. doi:10.1172/JCI44855 ing and how this adaptive pathway could be exploited for anticancer strategies in humans.

\section{Results}

Bimodal control of mitochondrial quality control by Hsp90s. To test a potential role of mitochondrial Hsp90s in global organelle protein folding, we used Gamitrinib ${ }^{\mathrm{TPP}}$ (GA mitochondrial matrix inhibitor, G-TPP) (15), a small molecule that combines the Hsp90 ATPase inhibitory module of 17-allylamino geldanamycin (17-AAG) (16) with the mitochondrial-targeting moiety of triphenylphosphonium (17). G-TPP is selectively delivered to mitochondria and does not affect Hsp90 homeostasis outside the organelle (15), i.e., chaperone client protein stability in the cytosol (11). As a model for these experiments, we selected glioblastoma, which exemplifies a highly malignant primary brain tumor in urgent need of fresh therapeutic approaches (18).

Within a 16-hour exposure, concentrations of G-TPP of 15-20 $\mu \mathrm{M}$ indistinguishably killed patient-derived and cultured glioblastoma cell lines (Figure 1A). Consistent with previous observations (15), this cell death response had the hallmarks of mitochondrial apoptosis, with loss of organelle inner membrane potential (Figure 1B), release of cytochrome $c$ in the cytosol (Figure 1C), activation of initiator caspase- 9 and effector caspase-3 and -7 (Figure 1D), and cellular reactivity for annexin $\mathrm{V}$ (Figure 1E). Because Hsp90s are selectively present in mitochondria of tumor cells, but not normal tissues (13), G-TPP did not kill normal fetal human astrocytes (FHAS) (Figure 1A). Under comparable conditions, nonsubcellularly targeted 17-AAG had no effect on normal or tumor cells (Figure 1).

Mechanistically, the "mitochondriotoxic" activity of G-TPP did not involve changes in expression of pro- or antiapoptotic Bcl-2 family proteins (Figure 2A) or recruitment of Bax to mitochondria (Figure 2B). Similarly, siRNA knockdown of mitochondrial "gatekeeper" proteins Bax and Bak did not affect cytochrome $c$ release (Figure 2C) or tumor cell death (Figure 2D) induced by Gamitrinib. 


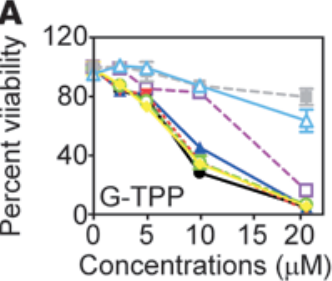

C

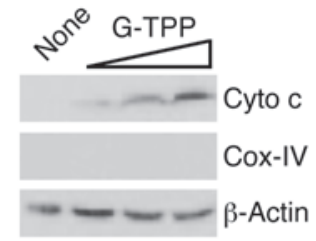

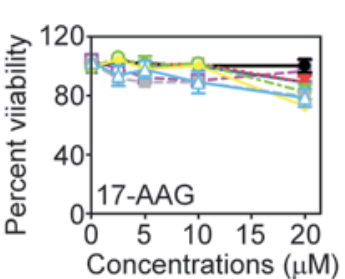

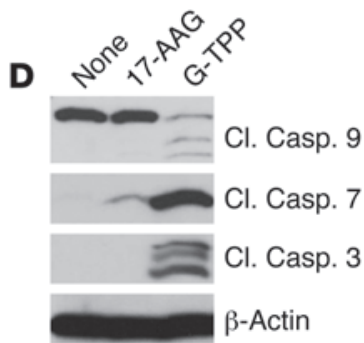

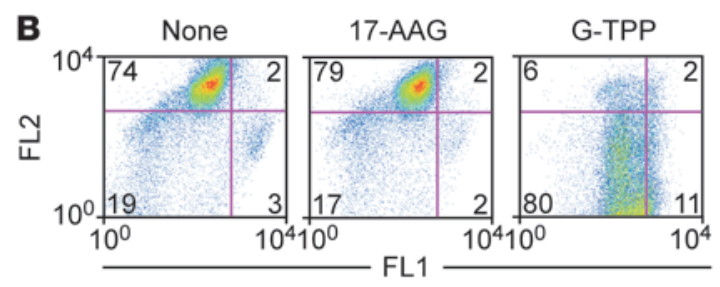

$\mathbf{E}$

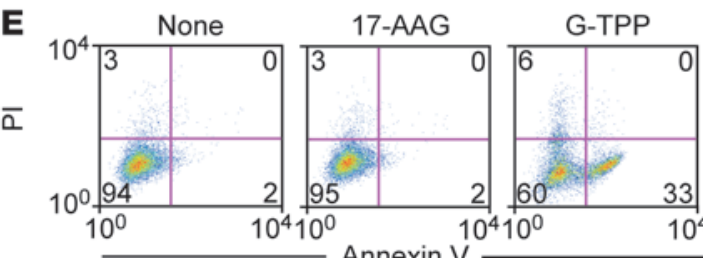

\section{Figure 1}

"Mitochondriotoxic" activity of G-TPP. (A) Cultured glioblastoma cell lines (U87, purple; LN229, blue; U251, black), patient-derived glioblastoma cells (GS620, yellow; GS48, green; AS515, red), or naive (gray), or SV40-transformed (light blue) normal FHAS were incubated with GamitrinibTPP (G-TPP, top) or 17-AAG (bottom) and analyzed for cell viability by MTT. Mean \pm SD of replicates. (B) U87 cells were treated with G-TPP or 17-AAG and analyzed for mitochondrial membrane potential by JC-1 staining and flow cytometry. FL1, green fluorescence channel; FL2, red fluorescence channel. (C and D) U87 cells were incubated with 0-20 $\mu \mathrm{M}$ G-TPP (C) or $20 \mu \mathrm{M}$ G-TPP or 17-AAG (D) and analyzed by immunoblotting. Cyto $c$, cytochrome c; Casp., caspase; Cl., cleaved. COX-IV was used as a mitochondrial marker. (E) U251 cells were treated as indicated and analyzed for annexin V/PI staining by flow cytometry. None, untreated. For $\mathbf{B}$ and $\mathbf{E}$, the percentage of cells in each quadrant is indicated.

As opposed to this direct mitochondriotoxic phenotype, glioblastoma cells exposed to suboptimal concentrations of Gamitrinib of 5-10 $\mu \mathrm{M}$ became completely filled with cytoplasmic vacuoles (Figure 3A). These structures contained subcellular material (Figure 3B) that comprised mitochondria, as determined by ImmunoGold labeling and electron microscopy (EM) with an antibody to COX-IV (Figure 3C). Instead, tumor cells treated with vehicle (Supplemental Figure 1, A and B; supplemental material available online with this article; doi:10.1172/ JCI44855DS1) or 17-AAG (Supplemental Figure 1, C and D) were unremarkable, with fine chromatin structure and normal organelles, and a nonbinding IgG was unreactive (Supplemental Figure 1E). Over time, G-TPP-treated cells also accumulated a lipidated form of the ubiquitin-like protein, dynein light chain 3 (LC3) (Figure 3D), and exhibited a punctate fluorescence pattern when transfected with an LC3 plasmid fused to GFP (Figure 3E). Collectively, these are all hallmarks of autophagy (19), a compensatory cellular response that attempts to preserve cell viability during stress by self-digesting damaged organelles (20). Accordingly, pharmacologic inhibitors of phagosome formation, bafilomycin A or 3-methyladenine (Figure 3F), or siRNA knockdown of the essential autophagy gene $\operatorname{atg} 5$ (Figure 3G), enhanced glioblastoma cell death induced by suboptimal concentrations of G-TPP (Figure $3 \mathrm{H}$ ).

Hsp90-directed mitochondrial UPR signaling. Next, we asked whether autophagy induced by suboptimal concentrations of Gamitrinib was due to loss of mitochondrial quality control, potentially from defects in organelle protein folding. Consistent with this model, mitochondria isolated from glioblastoma cells treated with noncytotoxic concentrations of G-TPP accumulated insoluble, i.e., unfolded proteins compared with control cultures (Figure 4A), suggestive of defective protein folding (9). This was associated with loss of mitochondrial superoxide dismutase
(Figure 4B), a stress sensor protein that becomes deregulated in response to mitochondrial damage $(20,21)$, whereas CypD was not affected (not shown).

There is prior evidence that mitochondria can undergo a UPR induced by organelle stress, including depletion of mitochondrial DNA (8), expression of unfolded matrix protein(s) (10), or deletion of organelle protease(s) (9), resulting in de novo activation of gene expression. Consistent with this model, G-TPP-treated cells exhibited extensive transcriptional changes by microarray analysis (Supplemental Table 1), with upregulation of multiple chaperones, a hallmark of mitochondrial UPR (10). As part of this gene signature, G-TPP induced the expression of stress response transcription factors $(2,7)$, CCAAT enhancer binding protein (C/EBP) homology protein (CHOP) (Figure 4C), and its dimerization partner C/EBP $\beta$ as early as 6 hours after treatment (Figure 4D and ref. 10). Instead, untargeted 17-AAG, which does not accumulate in mitochondria (15), had no effect on the level of organelle superoxide dismutase (Figure 4B), or expression of stress response transcription factors (Figure 4E).

As an independent approach to pharmacologic targeting with Gamitrinib, we next silenced potential effectors of this pathway. First, siRNA knockdown of mitochondrial Hsp90-like TRAP-1, one of the targets of Gamitrinib (15), also increased the expression of CHOP and C/EBP $\beta$ in glioblastoma cells (Figure 4F). Second, we produced clones of tumor cells with stable shRNA silencing of CypD, a component of the mitochondrial permeability transition pore (14), and substrate of organelle Hsp90s (13). Cultures stably transduced with control virus contained low levels of CHOP, whereas shRNA silencing of CypD significantly upregulated CHOP expression in glioblastoma cultures (Figure 4G).

Next, we examined the specificity of this response and looked at the effect of high, i.e., mitochondriotoxic concentrations of Gamitrinib on markers of cell survival and organelle UPR. Differently 

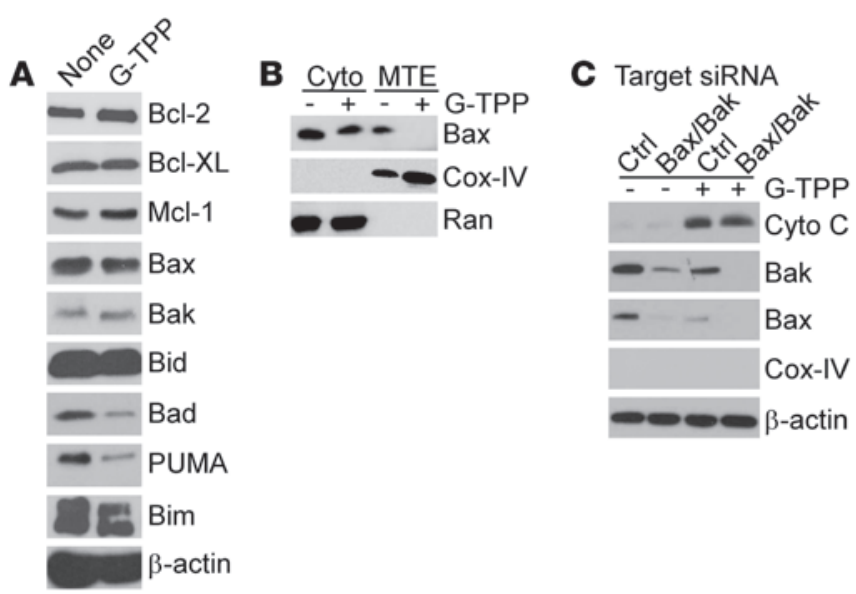

\section{Figure 2}

G-TPP-mediated mitochondrial dysfunction is independent of Bcl-2 proteins. (A) U87 cells were incubated with 0-10 $\mu \mathrm{M}$ G-TPP for 16 hours and analyzed by immunoblotting. (B) LN229 cells were treated with or without G-TPP and cytosol (Cyto) or mitochondrial extracts (MTE) and were analyzed after 6 hours by immunoblotting. (C) LN229 cells were transfected with control (Ctrl) or Bax-and Bak-directed siRNA, treated with G-TPP, and analyzed after 16 hours by immunoblotting. (D) The experimental conditions are as in C, except that control or Bax/Bak knockdown cells were analyzed for cell viability by MTT. Mean \pm SD of replicates.

from the results above, concentrations of G-TPP that directly induce collapse of mitochondrial integrity and cell death $(10-20 \mu \mathrm{M}$; Figure 1) did not upregulate CHOP or C/EBP $\beta$ levels in glioblastoma cells (Figure 4H). Instead, this response was associated with decreased levels of various survival factors, including Akt/ phosphorylated Akt, survivin, XIAP, and Bcl-2 (Figure 4I), potentially due to loss of cell viability under these conditions (Figure 1).

Modulation of NF- $\mathrm{K} B$-dependent gene expression by mitochondrial UPR. We next asked whether this transcriptional UPR affected tumor cell survival. G-TPP treatment of glioblastoma cells resulted in complete ablation of NF- $\mathrm{KB}$-mediated gene expression (22), either constitutively (Figure 5A) or after stimulation with TNF- $\alpha$ (Figure 5B). This was associated with rapid downregulation of multiple NF- $\mathrm{KB}$ target genes, including FLIP promoter activity (Figure 5C) and protein expression (Figure 5D) as well as RelB and Bcl-3 mRNA (Figure 5E). In contrast, Hsp70 levels were increased at low concentrations of G-TPP (Figure 5D), thus consistent with the induction of chaperones observed in microarray analysis (Supplemental Table 1). Gamitrinib did not exert a generic suppressive effect on gene expression, as etoposide-mediated induction of p53 luciferase promoter activity was unaffected by G-TPP (Figure 5F). As control, untargeted 17-AAG had no effect on NF-KB or FLIP promoter activity (Figure $5 \mathrm{G}$ ).

We next asked whether the transcriptional effectors of mitochondrial UPR, CHOP, and/or C/EBP $\beta$ mediated the inhibition of NF-KB activity under these conditions. siRNA silencing of CHOP (Figure 6A) produced constitutively higher NF-KB activity in glioblastoma cells, as compared with control transfectants (Figure 6B), and partially restored NF-KB-dependent transcription in the presence of G-TPP (Figure 6B). Reciprocally, glioblastoma cells transfected with CHOP or C/EBP $\beta$ (Figure 6C) exhibited reduced NF- $\mathrm{KB}$ activity in response to TNF- $\alpha$, whereas a control plasmid had no effect (Figure 6D). To determine whether CHOP DNA binding was required for inhibition of NF- $\mathrm{KB}$, we next transfected glioblastoma cells with a CHOP mutant that lacks the leu-

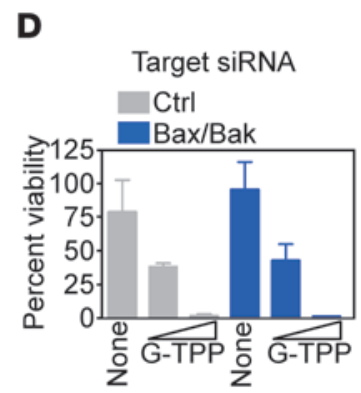

cine zipper domain ( $\Delta$-Leu) (23). Expression of this CHOP mutant, but not control pcDNA, suppressed NF- $\mathrm{\kappa B}$ activity in response to TNF- $\alpha$ indistinguishably from WT CHOP (Figure 6E).

We next compared mitochondrial UPR modulation of NF- $\mathrm{KB}$ with other pathways of organelle regulation of gene expression, including ER stress response (7) or mitochondrial retrograde signaling (1). In these experiments, mitochondrial depolarization induced by the uncoupler, carboxy cyanide 3-chlorophenyl hydrazone (CСCP) resulted in increased NF- $\kappa \mathrm{B}$ activity in tumor cells (Supplemental Figure 2A), whereas induction of mitochondrial apoptosis by the cell death stimulus staurosporine (STS) had no effect on NF-KB promoter activity (Supplemental Figure 2B).

Exploitation of mitochondrial UPR for cancer therapy. NF-КВ executes a broad survival program in tumor cells (22), blunting cell death stimuli that activate the extrinsic, i.e., death receptor pathway of apoptosis (24). Therefore, we asked whether loss of NF-кB activity by Gamitrinib sensitized tumor cells to TNF- $\alpha$-related apoptosis-inducing ligand (TRAIL), a death receptor agonist currently evaluated in the clinic as an anticancer regimen (24). Treatment of cultured or patient-derived primary glioblastoma cells (Figure 7A) as well as breast or prostate adenocarcinoma cells (Figure 7B) with TRAIL did not result in significant loss of cell viability, consistent with the known resistance to TRAIL of various tumor types (24). In contrast, the combination of TRAIL plus noncytotoxic concentrations of G-TPP that activate mitochondrial UPR efficiently killed all tumor cell types tested (Figure 7, A and B). Consistent with a tumor selectivity of this response, normal FHAS were not affected (Figure 7B).

Mechanistically, the TRAIL plus Gamitrinib combination synergistically stimulated mitochondrial damage, with more accelerated loss of inner membrane potential (Figure 7C), enhanced release of cytochrome $c$ from mitochondria (Figure 7D), cellular reactivity for annexin $V$ (Figure 7E), and faster activation of initiator caspase- 8 and -9 , as well as effector caspase- 3 and -7 , as early as 2 hours after treatment (Figure 7F). In addition to mitochondrial dysfunction, this response also required death receptor signaling (24), as transfection of the caspase-8 inhibitor CrmA (Figure 8A), siRNA silencing of caspase- 8 (Figure $8 \mathrm{~B}$ ), or reintroduction of FLIP (Figure 8C) all partially reversed cell killing induced by the TRAIL plus G-TPP combination (Figure 8, A-C), and attenuated caspase-3 processing (Figure $8 \mathrm{~B}$ and not shown).

To verify that the synergy between TRAIL and G-TPP was due to removal of NF-KB-mediated cell survival, we next stably silenced the IKK kinase and NF-KB activator, TGF- $\beta$-activated kinase 1 (TAK1) in tumor cells and selected clones with intermediate (no. 41), or complete (no. 61) loss of TAK1 (Figure 8D). In these experiments, TRAIL plus G-TPP indistinguishably killed control pLKO 

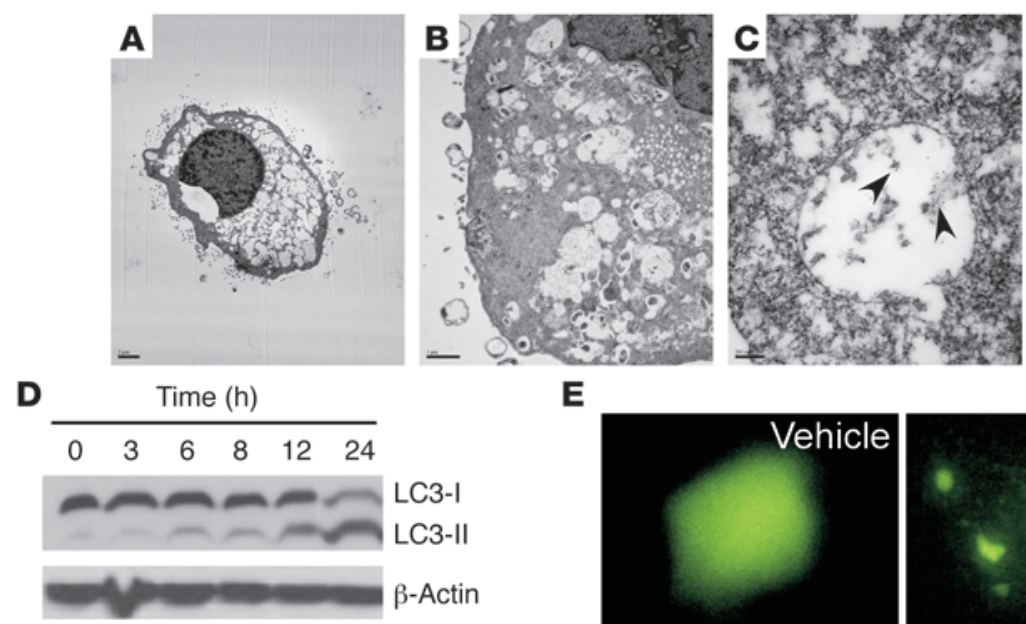

E
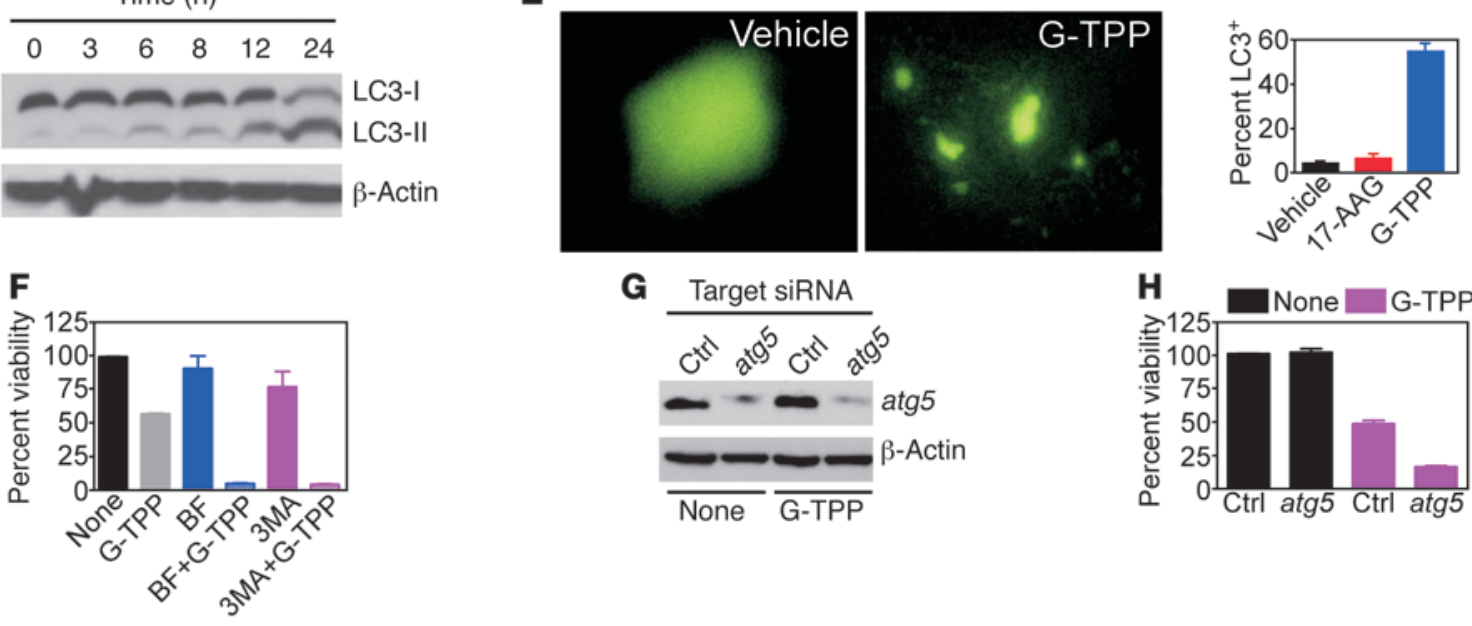

G Target siRnA

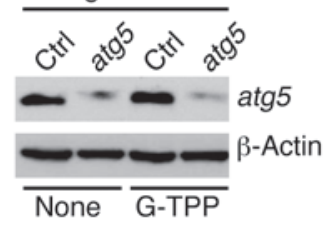

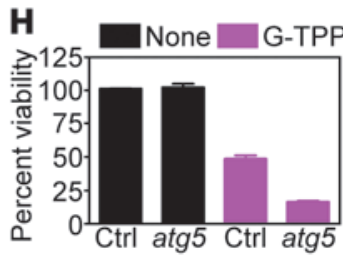

\section{Figure 3}

Mitochondrial Hsp90 regulates autophagy. (A-C) LN229 cells were treated with G-TPP and analyzed by EM (A and B) or immunoelectron microscopy with an antibody to COX-IV (C). Arrowheads, COX-IV-reactive material. Scale bars: $2 \mu \mathrm{m}$ (A); $1 \mu \mathrm{m}$ (B); $200 \mathrm{~nm}$ (C). (D) U87 cells were treated with G-TPP, harvested at the indicated time intervals, and analyzed by immunoblotting. The position of the unmodified (I) or lipidated (II) form of LC3 is indicated. (E) U251 cells were transfected with LC3-GFP, treated with vehicle or G-TPP, and analyzed after 16 hours by fluorescence microscopy (left). The percentage of cells with punctate GFP fluorescence was quantified (right). Mean \pm SD of 4-6 independent microscopy fields. (F) U87 cells were incubated with inhibitors of phagosome formation, bafilomycin A (BF), or 3-methyladenine (3-MA) for 1 hour, treated with G-TPP, and analyzed after 16 hours by MTT. Mean \pm SD of replicates. (G) L229 cells were transfected with control or atg5directed siRNA and analyzed by immunoblotting. (H) siRNA-transfected LN229 cells as in G were analyzed for cell viability after 16 hours by MTT. Mean \pm SD of replicates.

or no. 41 transfectants, whereas ablation of TAK1 (clone no. 61) significantly reversed cytotoxicity induced by the 2 agents combined (Figure 8E). As an independent approach, we next transfected glioblastoma cells with a mutant form of IкB $\alpha$ that functions as a dominant negative antagonist of NF- $\mathrm{KB}$ activation. Expression of this I $\mathrm{B} \alpha$ "super-repressor" mutant significantly reversed cell killing induced by Gamitrinib plus TRAIL, whereas a control plasmid had no effect (Figure 8F). Finally, we looked at a potential requirement of proapoptotic Bcl-2 family member Bax on this cell death response. WT HCT116 cells were efficiently killed by the TRAIL-G-TPP combination, whereas each agent alone had intermediate effect (Figure 8G). In contrast, and at variance with the direct mitochondriotoxic activity of G-TPP alone (Figure 2), homozygous deletion of Bax in HCT116 cells partially rescued apoptosis induced by G-TPP plus TRAIL (Figure 8G).

Antiglioma activity of targeting a mitochondrial UPR in vivo. Next, we asked whether the combination of TRAIL plus Gamitrinib had activity against glioblastoma in vivo (18). Luciferase-expressing U87 glioblastoma cells implanted in the right cerebral striatum of immunocompromised mice gave rise to rapidly growing tumors by bioluminescence imaging, and treatment of these mice with vehicle, stereotactic delivery of TRAIL, or systemic administra- tion of suboptimal concentrations of G-TPP did not affect tumor growth in vivo (Figure 9A). Similarly, systemic monotherapy with G-TPP at concentrations ( $20 \mathrm{mg} / \mathrm{kg}$ as daily i.p. injections) that inhibit subcutaneous xenograft tumor growth in mice (15) had no effect on orthotopic glioblastoma growth (Figure 9B). In contrast, 2 cycles of intracranial TRAIL combined with systemic G-TPP suppressed the growth of established glioblastomas (Figure 9A), with no significant animal weight loss throughout treatment (Figure 9C). Analysis of brain sections from these mice, but not single agent-treated animals (Supplemental Figure 3), showed loss of tumor cell proliferation, internucleosomal DNA fragmentation, and caspase-3 activity, consistent with extensive activation of apoptosis in vivo (Figure 9D). Also, these tumors, but not areas of normal brain, including hippocampus or cortex, showed nuclear reactivity for CHOP (Figure 10A), suggesting that a mitochondrial UPR was activated in vivo. To determine whether a similar pathway occurred in cancer patients, we next examined WHO grade IV glioblastoma specimens by immunohistochemistry. A strong expression of nuclear CHOP was observed in primary glioblastomas, but not normal brain, and this reactivity was especially prominent in tumor cells bordering areas of necrosis in vivo (Figure 10B). 
A

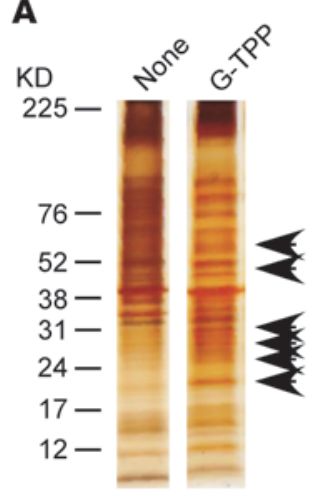

B

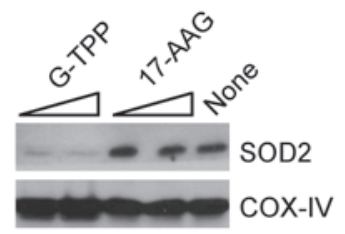

C

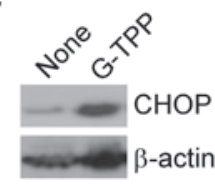

D

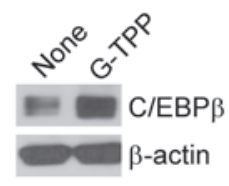

E

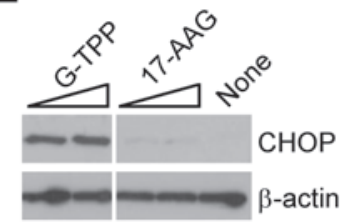

$\mathbf{F}$

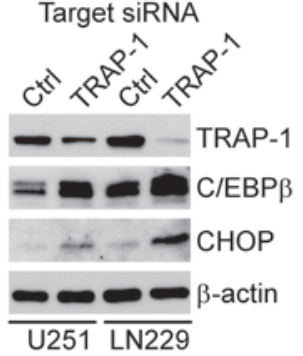

G Target shRNA

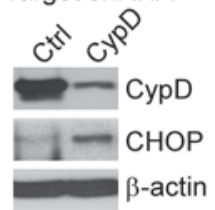

H $\mathrm{G-TPP}(\mu \mathrm{M})$

$\begin{array}{lll}0 & 5 & 10\end{array}$

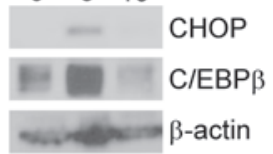

noseres $\beta$-actin

I

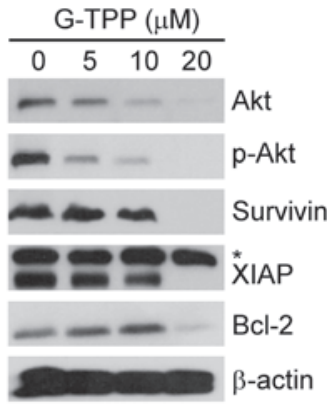

Figure 4

Targeting mitochondrial Hsp90 induces organelle UPR. (A) Detergent-insoluble mitochondrial proteins from control (none) or G-TPP-treated LN229 cells were visualized by silver staining. Arrowheads, insoluble, i.e., unfolded proteins. (B-E) LN229 cells were treated as indicated and analyzed by immunoblotting. SOD2, mitochondrial superoxide dismutase. $(\mathbf{F})$ The indicated glioblastoma cells were transfected with control or TRAP-1-directed siRNA and analyzed by immunoblotting. (G) LN229 cells were stably transfected with control or CypD-directed shRNA and analyzed by immunoblotting. (H-I) LN229 cells were incubated with the indicated concentrations of G-TPP and analyzed by immunoblotting after 6 hours (H) or 16 hours (I). p-Akt, phosphorylated Akt; *Nonspecific.

\section{Discussion}

In this study, we have shown that mitochondrial Hsp90 chaperones (13) function as arbiters of organelle-compartmentalized protein folding, especially in cells with high demands for mitochondrial biogenesis and energy production, i.e., tumor cells. Targeting of this pathway with small molecule Hsp90 inhibitors selectively delivered to mitochondria, i.e., Gamitrinib ${ }^{\mathrm{TPP}}$ (15), produces a bimodal response, with high concentrations of Gamitrinib triggering catastrophic organelle collapse, independently of Bcl-2, and immediate tumor cell death, whereas suboptimal inhibition of mitochondrial Hsp90 stimulates a compensatory organelle UPR aimed at restoring homeostasis $(10,25)$ via autophagy $(19)$ and a stress response gene expression signature $(2,4,7)$. One of the consequences of this transcriptional UPR is a complete suppression of NF- $\mathrm{kB}$-dependent gene expression. In turn, this shuts off multiple prosurvival mediators, confers sensitivity of resistant tumor types to a death receptor agonist, i.e., TRAIL, and suppresses intracranial glioblastoma growth in mice without detectable organ or systemic toxicity.

The recent identification of an abundant pool of Hsp90 chaperones comprising Hsp90 and its related molecule, TRAP-1, in mitochondria of tumor cells (13) has expanded the subcellular localization of these chaperones and pointed to their potential pivotal role in organelle-compartmentalized protein folding (26), potentially exploited in malignancy. In this context, Hsp90-like chaperones oversee protein folding quality control in the ER (27), contributing to dynamic adaptation during changing metabolic environments, and aberrations of this pathway sensed by ER lumenal transmembrane proteins trigger an evolutionary conserved (2), tripartite compensatory UPR (7). Conversely, the regulatory networks that control the protein folding environment in mitochondria have remained largely elusive, complicated by the complex architecture of the organelle, its production of protein-altering reactive oxygen species (28), and the dual role of matrix proteases and chaperones in both preprotein import and (re)folding (29).

Here, pharmacologic inhibition of mitochondrial Hsp90s by Gamitrinib, or their genetic silencing by siRNA triggered classical hallmarks of a mitochondrial UPR, including accumulation of unfolded proteins, deregulated expression of organelle stress sensor protein(s), upregulation of stress-response transcription factors CHOP and C/EBP $\beta$, and downstream induction of a compensatory gene expression signature, comprising several chaperones, such as Hsp70 (30). This is in line with the mitochondrial stress response induced by less physiologic stimuli, including depletion of organelle DNA (8), forced expression of unfolded matrix protein(s) (10), or deletion of quality control protease(s) (9). How the mitochondrial UPR induced under these conditions (8-10) or by targeting organelle Hsp90 (this study) couples to nuclear activation of gene expression remains to be fully elucidated. In the model of Caenorbabditis elegans, this pathway may involve the generation of diffusible peptides generated via the ATP-dependent matrix protease ClpXP that in turn affect nuclear gene transcription (31). Alternatively, mitochondrial dysfunction induced by Gamitrinib potentially coupled with changes in organelle bioenergetics (32) may activate the stresssensing machinery at the mitochondria-ER interface (33), activating a secondary ER stress response that in turn influences gene expression. In support of this interorganelle communication model (34), tumor cells treated with Gamitrinib exhibited upregulation of the ER chaperone Grp78 and phosphorylation of the PERK substrate eIF2 $\alpha$ (our unpublished observations), 2 markers of ER stress (7).

A distinctive feature of the mitochondrial UPR described here is the activation of autophagy. In agreement with a prevailing consensus (35), this response provided a compensatory attempt 


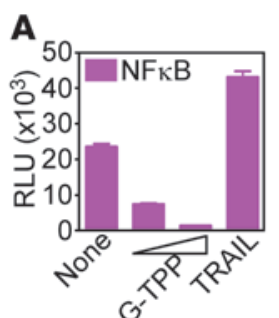

$\mathbf{E}$

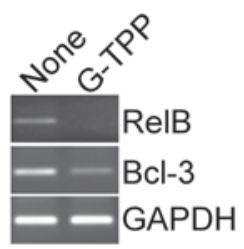

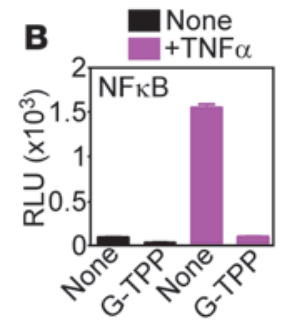

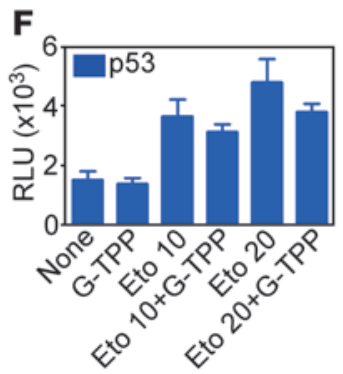

C

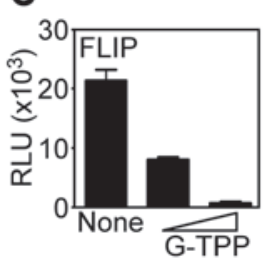

G

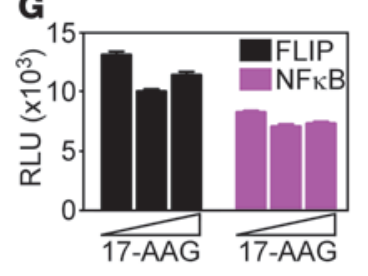

D

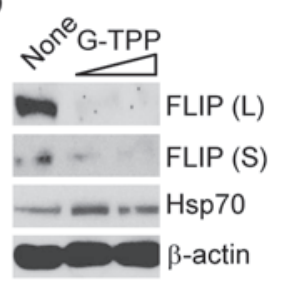

Time (h)

\begin{tabular}{lll}
\hline 0 & 816
\end{tabular}

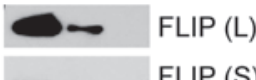

FLIP (S)

$\beta$-actin

\section{Figure 5}

Mitochondrial UPR suppresses NF-кB activity. (A-C) U251 cells were treated as indicated and analyzed for $\beta$-galactosidase-normalized NF- $\mathrm{KB}(\mathbf{A}$ and $\mathbf{B})$ or FLIP $(\mathbf{C})$ luciferase promoter activity in a luminometer in the absence (A and $\mathbf{C})$ or presence of TNF- $\alpha(\mathbf{B})$. TRAIL $(800 \mathrm{ng} / \mathrm{ml})$ was used as control. Mean \pm SD of replicates. (D) G-TPP-treated LN229 cells were analyzed by immunoblotting. Top, dose-response; bottom, time-course. L, FLIP long form; S, FLIP short form. (E) G-TPP-treated LN229 cells were analyzed by PCR. (F) MCF-7 cells were treated as indicated and analyzed after 5 hours for $\beta$-galactosidase-normalized p53 luciferase promoter activity. (G) U251 cells were treated with nontargeted 17-AAG and analyzed after 8 hours for NF-kB or cFLIP luciferase promoter activity. Mean \pm SEM of replicates of a representative experiment.

conditions has not been previously reported. This pathway differed from previous models of organelle-coupled transcriptional responses, as mitochondrial retrograde signaling in response to $\mathrm{mTOR}$ activation (1) or activation of ER UPR (7) has been instead associated with an increase in NF- $\mathrm{kB}$ activation. Conversely, there is precedence for a role of ER stress in suppressing NF- $\mathrm{KB}$ activity during inflammatory responses (40) via upregulation of $\mathrm{C} / \mathrm{EBP} \beta$ and CHOP (23). Here, suppression of NF- $\mathrm{\kappa B}$ activity by Gamitrinib caused the acute loss of multiple downstream NF-KB effector genes, including mediators of apoptosis resistance, such as FLIP (24). Consequently, concentrations of Gamitrinib that activate mitochondrial UPR but do not directly trigger cell death potently synergized with the death receptor agonist TRAIL,

to remove damaged mitochondria and maintain cell survival (19), and, accordingly, genetic or pharmacologic antagonists of autophagy enhanced Gamitrinib-induced tumor cell killing. Although a link between autophagy and mitochondrial UPR has not been previously recognized, there is evidence for an evolutionary-conserved role of autophagy in ER UPR (36), potentially involving IRE1 regulation of JNK (37). Also in agreement with the findings presented here is the observation that autophagy contributes to mitochondrial quality control in human diseases (38). Accordingly, the mitochondrial kinase PINK1 has been implicated in promoting autophagic removal of damaged mitochondria in neurons via interactions with Parkin and, potentially, Beclin-1 (39).

Although the identification of CHOP and C/EBP $\beta$ as transcriptional effectors of mitochondrial UPR is consistent with current paradigms of organelle-compartmentalized stress response (30), the suppression of NF-kB activity observed under these

\section{Figure 6}

Mitochondrial UPR regulation of NF- $\kappa B$ activity. (A) LN229 cells transfected with control or CHOP-directed siRNA were treated with G-TPP and analyzed by immunoblotting. (B) siRNA-transfected LN229 cells as in A were treated with G-TPP and analyzed for NF- $\mathrm{B}$ luciferase promoter activity, with or without TNF- $\alpha$. Mean \pm SD of replicates. ${ }^{\star} P=0.018 ;{ }^{* * *} P=0.0007$. (C) LN229 cells were transfected with the indicated plasmids and analyzed by immunoblotting. (D) Transfected LN229 cells as in $\mathbf{C}$ were analyzed for NF-KB luciferase promoter activity in the presence of TNF- $\alpha$. Mean \pm SD of replicates. ${ }^{*} P=0.02$; ${ }^{* \star} P=0.0021$. (E) LN229 cells transfected with pcDNA or a CHOP mutant lacking the leucine zipper (CHOP- $\Delta$ Leu) were analyzed for $\mathrm{NF}-\kappa \mathrm{B}$ luciferase promoter activity with or without TNF- $\alpha$. Mean \pm SD of replicates. ${ }^{\star \star \star} P=0.0006$. causing mitochondrial collapse, caspase-dependent apoptosis, and suppression of intracranial glioblastoma growth in rodents.

Despite the considerable interest in apoptosis-based anticancer therapies (41), the efficacies of these approaches is often impaired by adaptive and resistance mechanisms in vivo. These challenges are exemplified by TRAIL, a potent activator of death-receptor apoptosis (24), whose efficacy is often reduced or nullified in many tumor types because of parallel activation of NF-кB-dependent survival (22). Conversely, the activation of

\section{A}
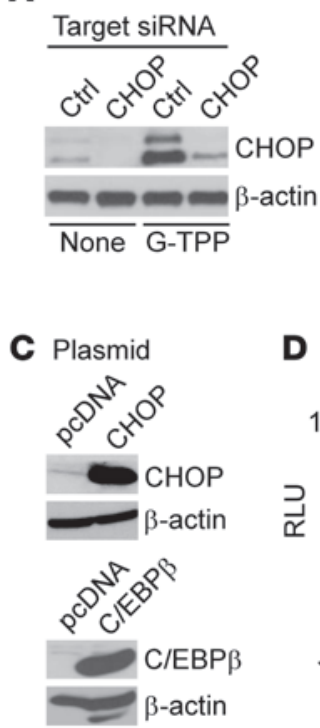

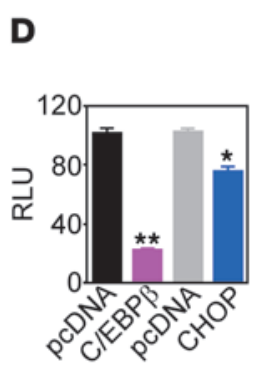

Target cDNA

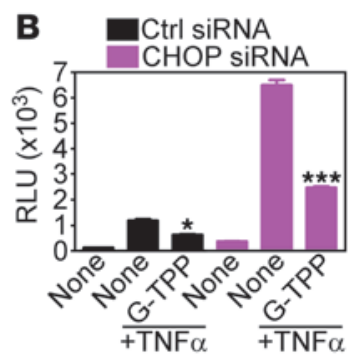

E

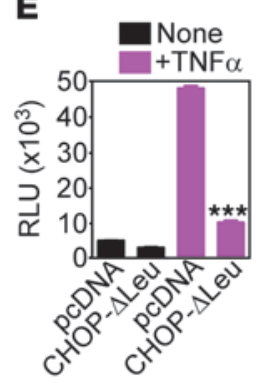

Target cDNA 
A

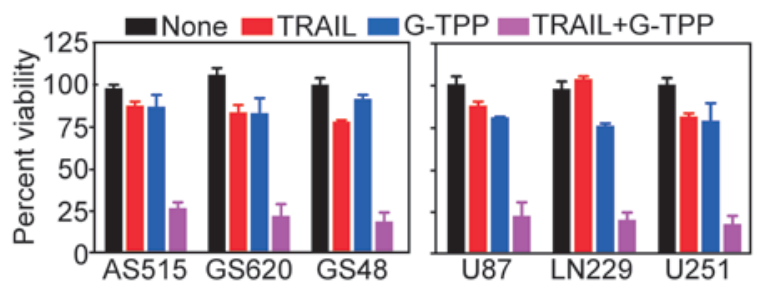

B

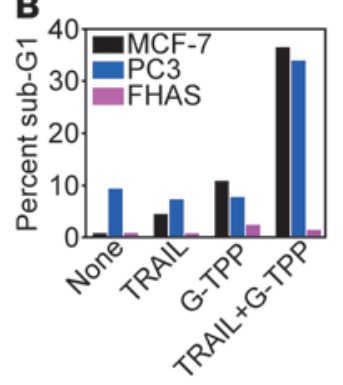

C

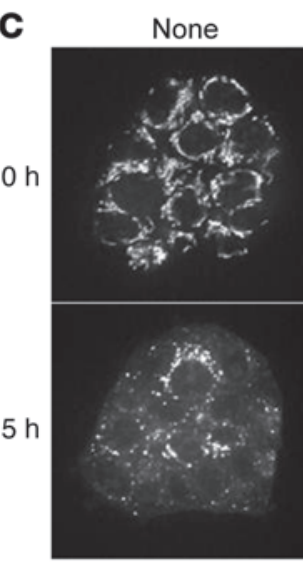

TRAIL

G-TPP

TRAIL+G-TPP

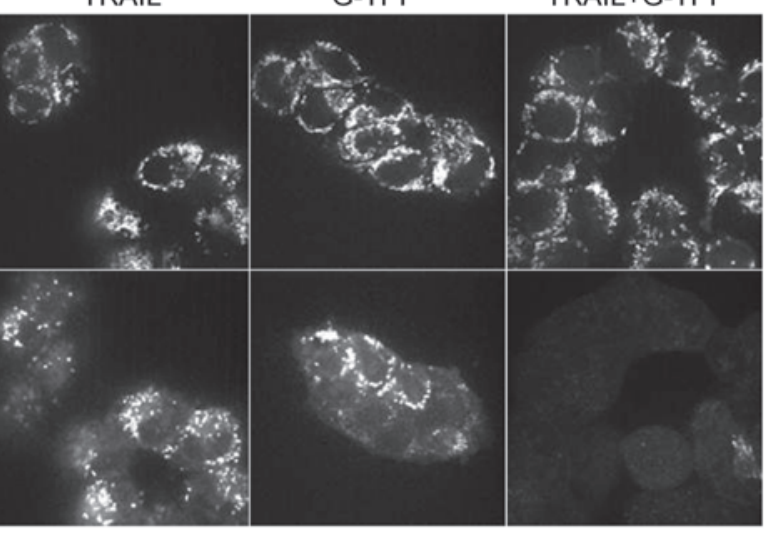

D

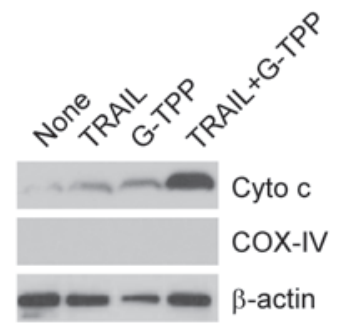

E

$$
\text { F }
$$

Time (h)
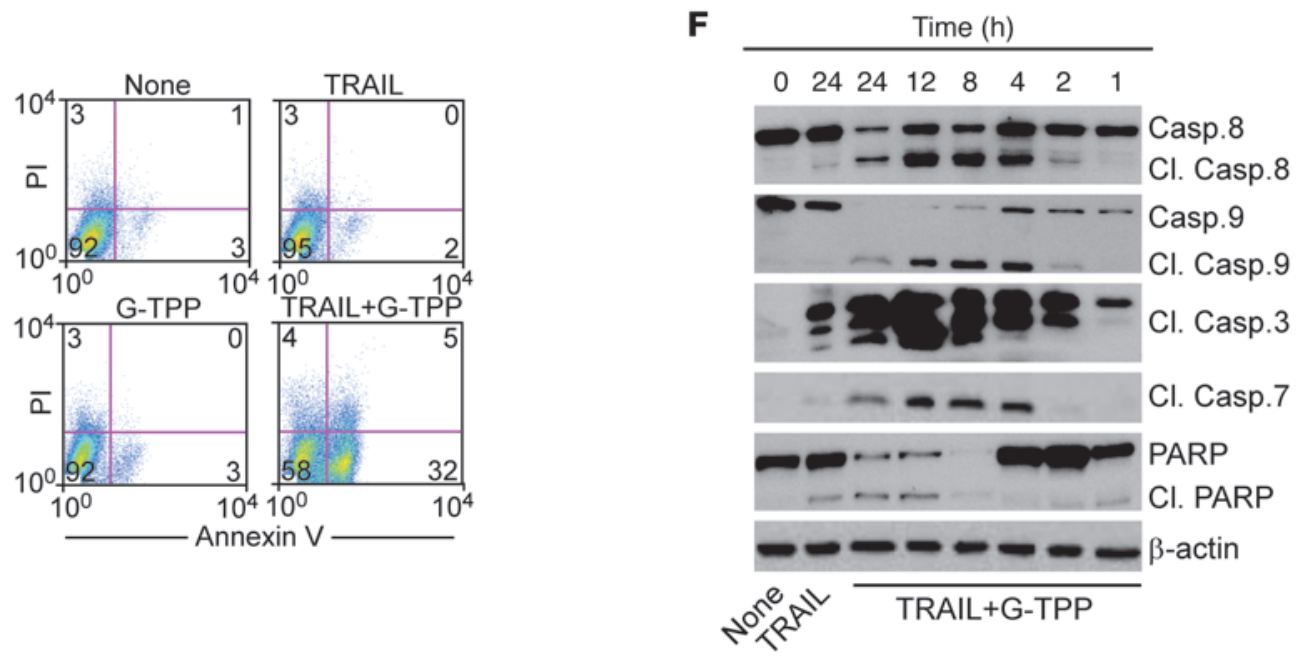

\section{Figure 7}

Exploitation of mitochondrial UPR for combination anticancer therapy. (A) Patient-derived (left) or cultured (right) glioblastoma cells were treated with TRAIL or G-TPP, alone or in combination, and analyzed by MTT. Mean \pm SD of replicates. (B) The indicated cell types were treated as in A and analyzed for DNA content by PI staining and flow cytometry. The percentage of cells with hypodiploid (sub-G1) DNA content is indicated. Representative experiment. (C) U251 cells were labeled with TMRM, treated as indicated, and analyzed for loss of mitochondrial membrane potential after 0 or 5 hours by confocal laser microscopy. Representative experiment. Original magnification, $\times 600$. (D) U251 cells treated as indicated were analyzed after 16 hours by immunoblotting. (E) Treated U251 cells were analyzed after 16 hours for annexin V/PI staining by flow cytometry. The percentage of cells in each quadrant is indicated. (F) Treated U87 cells were analyzed after the indicated time intervals by immunoblotting. $\mathrm{Cl}$, cleaved.

mitochondrial UPR by noncytotoxic concentrations of Gamitrinib removed this prosurvival environment, restoring sensitivity to TRAIL-mediated apoptosis of resistant tumor types, including patient-derived glioblastoma cells. Importantly, the combination of TRAIL plus Gamitrinib was devoid of significant organ or systemic toxicity in our preclinical glioblastoma model in vivo. This may reflect the tumor selectivity of each agent alone
(15) reported in earlier studies (24), but also the nearly exclusive exploitation of mitochondrial Hsp90s in tumors, as opposed to normal tissues (13).

Although with potential cell type-specific differences (42), a prevailing consensus suggests that organelle UPR signaling is broadly activated in human cancer, promoting tumor growth and disease progression in vivo (3). Consistent with this model, 
A
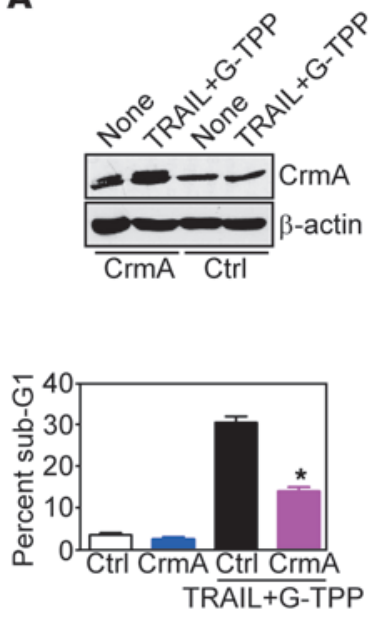

D
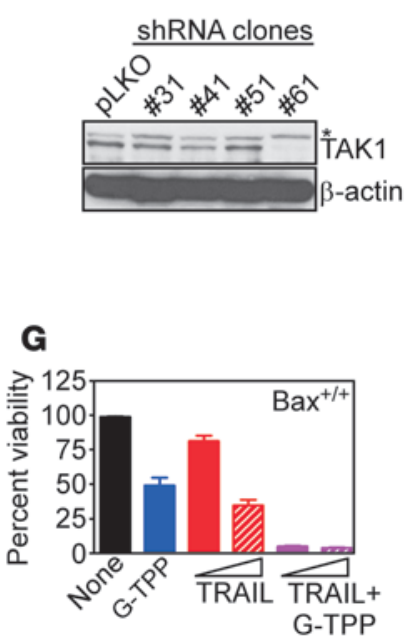

B
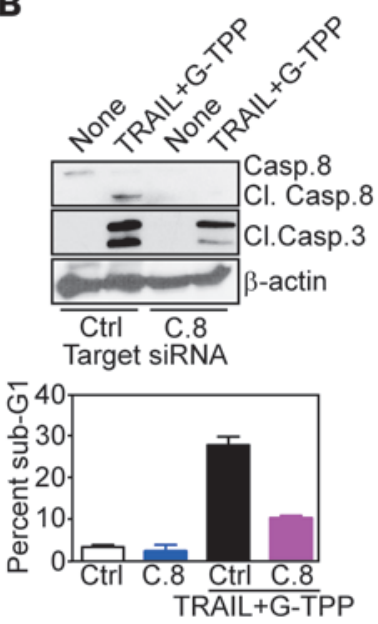

E
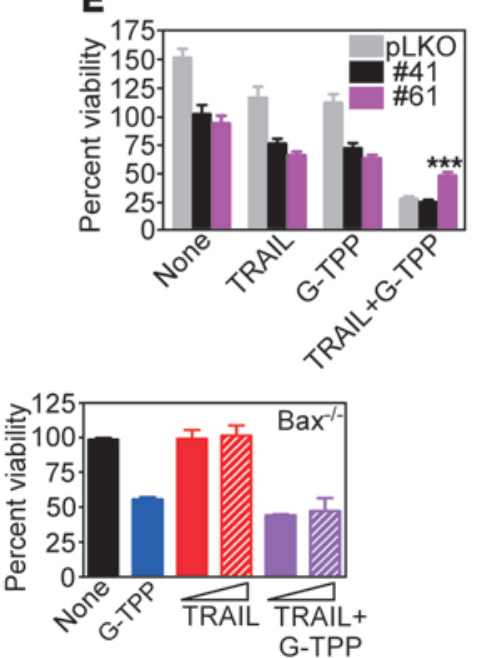

C
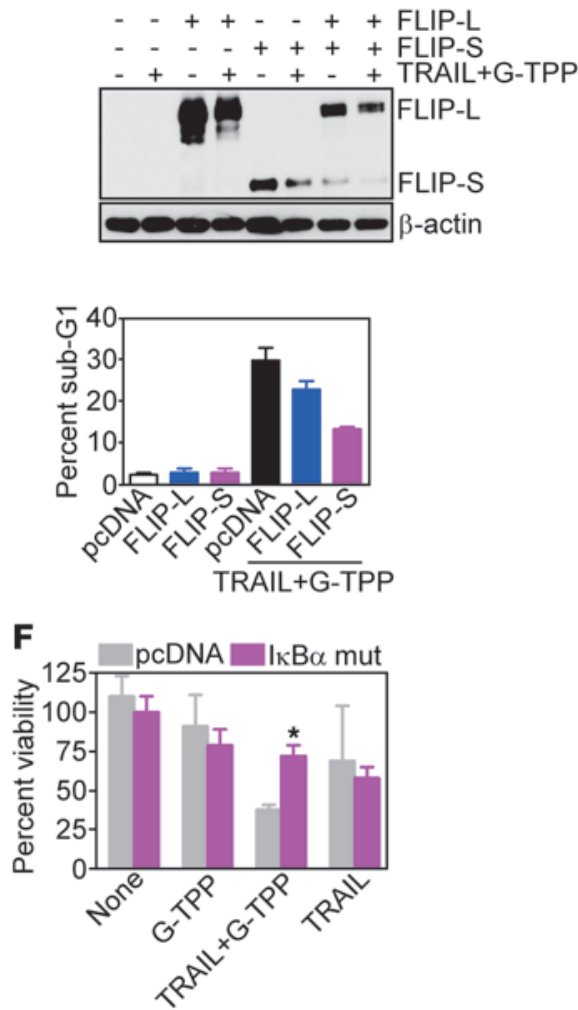

Figure 8

TRAIL plus Gamitrinib anticancer activity. (A-C) LN229 cells were transfected with control, CrmA (A), caspase-8 (C.8) (B), or FLIP (C) cDNA, treated with the combination of TRAIL plus G-TPP, and analyzed after 16 hours by immunoblotting (top), or PI staining and flow cytometry (bottom). The percentage of cells with hypodiploid (sub-G1) DNA content is indicated. Mean \pm SEM of replicates. ${ }^{*} P=0.011-0.032 ;(D$ and E) MCF-7 cells were stably transfected with control lentivirus (pLKO) or lentivirus encoding TAK-1-directed shRNA, and stable clones (\#) were analyzed by immunoblotting (D) or cell viability by MTT (E). *Nonspecific. Mean \pm SEM of replicates. ${ }^{* \star *} P<0.0001$. (F) LN229 cells were transfected with control or $\mathrm{I}_{\kappa} \mathrm{B} \alpha$ "super-repressor" mutant $\mathrm{CDNA}$, treated as indicated, and analyzed for cell viability by MTT. Mean \pm SEM of replicates. ${ }^{*} P=0.01$. (G) $\mathrm{Bax}^{+/+}$(left) or $\mathrm{Bax}^{-/-}$(right) HCT116 cells were treated as indicated and analyzed for cell viability by MTT. Mean \pm SEM of replicates.

we observed here increased expression of $\mathrm{CHOP}$ in an orthotopic glioblastoma model as well as primary tumor specimens collected from glioblastoma patients in vivo. The underlying stimulus for this UPR in vivo has not been identified, but it is intriguing that high levels of nuclear CHOP in glioblastoma patients were observed in tumor cells bordering areas of necrosis, thus likely exposed to insufficient vascularization. This is consistent with a role of hypoxia and its pivotal mediator, HIF-1, in promoting autophagy and UPR activation in vivo (43).

In summary, we have shown that mitochondrial Hsp90 chaperones (13) maintain a compartmentalized protein folding environment and organelle quality control (30), especially in tumor cells. Consistent with the concept that targeting stress response pathways may be beneficial for the treatment of human diseases
(6), disabling mitochondrial Hsp90 (15) and exploiting its associated UPR (this study) may offer concrete prospects for cancer therapy (44). Based on the proof-of-concept results presented here, such an approach may be broadly applicable to genetically disparate tumors, enhance the currently modest activity of apoptosis modifiers (45) or Hsp90 antagonists (12), and provide desirable selectivity for tumor versus normal tissues in vivo.

\section{Methods}

Patient samples. Twelve surgically resected samples of WHO grade IV glioblastomas containing adjacent normal brain were collected and analyzed anonymously as discarded tissues, by immunohistochemistry. The patient population comprised both males and females 27 to 79 years of age. Informed consent was obtained from all patients prior to surgery. 
A
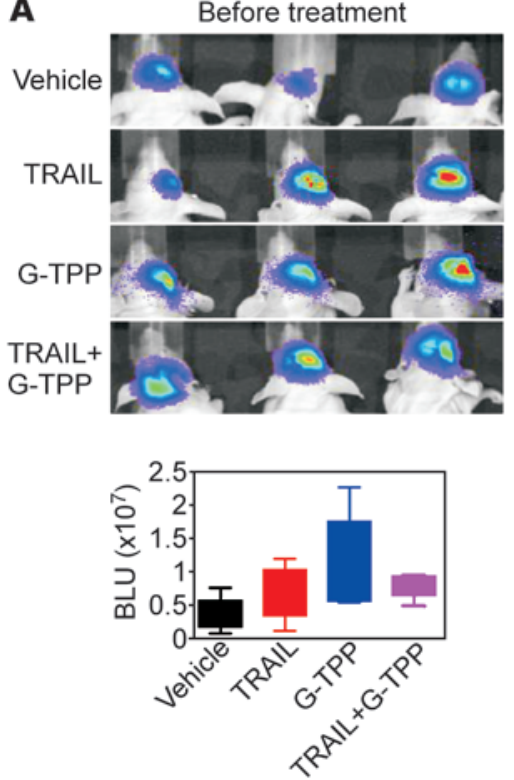

D
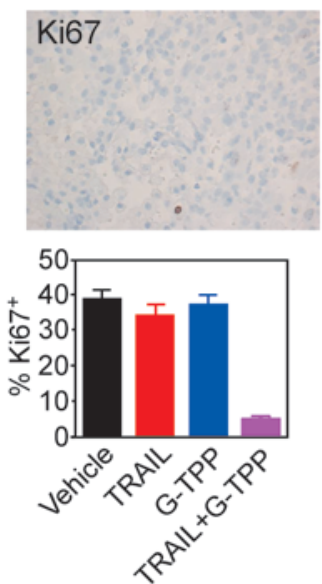

After treatment
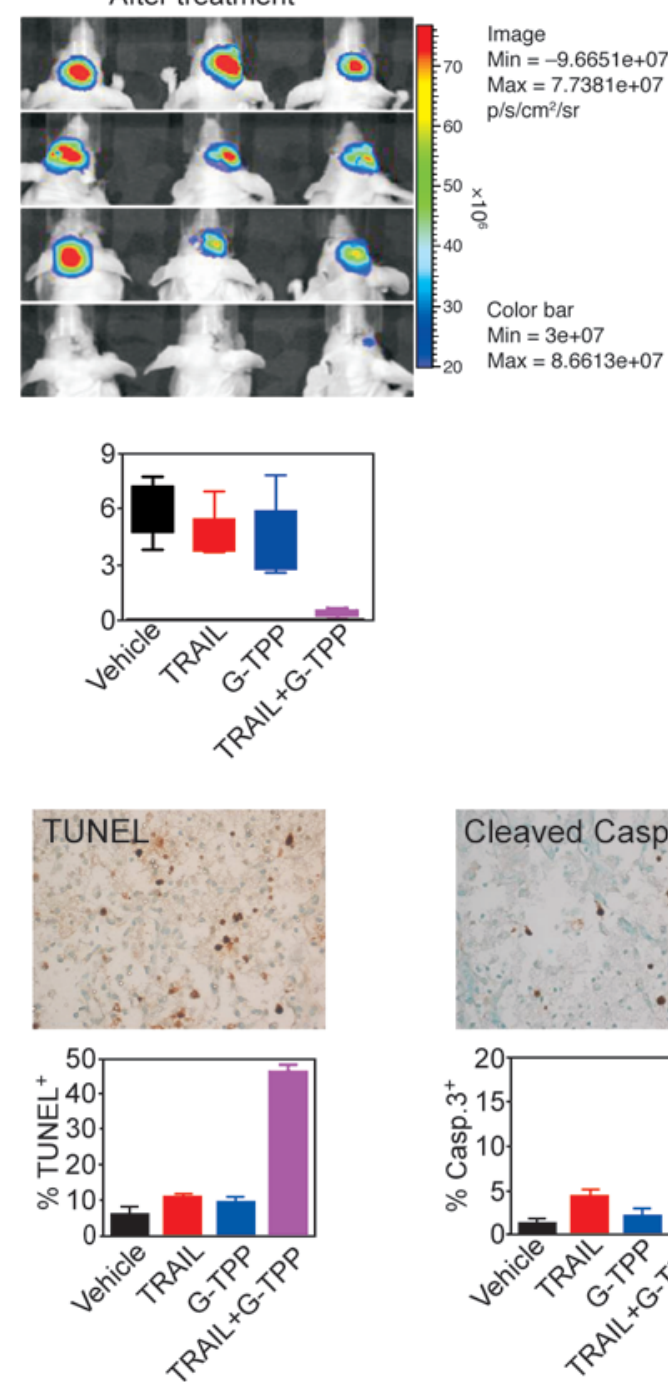

B

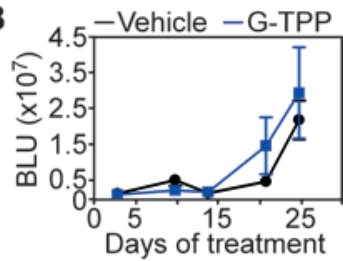

C

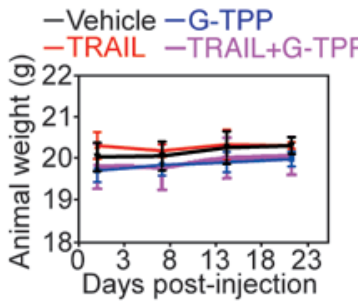

Figure 9

Exploitation of mitochondrial UPR for antiglioma therapy in vivo. (A) Nude mice carrying intracranial U87-Luc glioblastomas were treated as indicated and analyzed by bioluminescence imaging (top). Bottom, quantification of bioluminescence signals before or after treatment. The statistical analysis of animal survival in the various groups at the end of the experiment is as follows: vehicle versus G-TPP, NS; vehicle versus TRAIL, NS; TRAIL (27 days) versus TRAIL+G-TPP (35 days), $P=0.0044$; G-TPP ( 25 days) versus TRAIL+G-TPP (35 days), $P=0.0017$; vehicle (24 days) versus TRAIL+G-TPP (35 days), $P=0.0014$. (B) Nude mice carrying established intracranial glioblastomas as in A were treated with vehicle or G-TPP monotherapy at $20 \mathrm{mg} / \mathrm{kg}$ as daily i.p. injections and analyzed by bioluminescence imaging. Mean \pm SEM of groups with mice as the individual units. $P=0.67$. (C) Nude mice as in A were monitored for weight changes during the various treatments. Mean \pm SD of individual groups. (D) Brain sections from TRAIL+G-TPP-treated mice were analyzed for cell proliferation (Ki67), internucleosomal DNA fragmentation (TUNEL), or active caspase-3 (top) by immunohistochemistry, and the percentage of positive cells was quantified (bottom). Original magnification, $\times 400$.

Cells and cell cultures. Human glioblastoma cell lines LN229 (p53 mutant; PTEN, WT), U87 (p53 WT; PTEN mutant), U251 (p53 mutant), prostate adenocarcinoma PC3, breast adenocarcinoma MCF-7, and human epithelial kidney (HEK) 293T were purchased from ATCC. Cells were cultured in DMEM Glutamax-I medium (Invitrogen) containing $10 \% \mathrm{FBS}$ and $1 \%$ penicillin/streptomycin (Invitrogen) at $37^{\circ} \mathrm{C}$ in a $10 \% \mathrm{CO}_{2}$ humidified atmosphere. Patient-derived cultures of glioblastoma cells were established from fresh, surgically resected samples of WHO grade IV and grade III glioblastomas (GS620, GS48, and AS515) obtained from the Division of Neurosurgery, University of Massachusetts Medical School. Tissue samples were minced in small pieces and transferred to plastic tissue culture flasks (Falcon; BD); culture outgrowths were established in DMEM medium containing $10 \% \mathrm{FCS}$ and $1 \%$ penicillin/streptomycin at $37^{\circ} \mathrm{C}$ in $10 \% \mathrm{CO}_{2}$. Upon reaching confluence, the cell monolayers were harvested by a brief incubation with trypsin/EDTA (Viralex; PAA Laboratories) and confirmed as mycoplasma free by staining with 4,6-diamidino-2 phenylindole (Roche Diagnostics). The glial origin of these cultures was confirmed by staining for $\alpha$-glial fibrillary acidic protein. In contrast, antibodies against endothelial cell markers, CD31 (Pharmingen), factor VIII (Dako), or neuronal neurofilament proteins 70, 160, and 200 (all from 
A

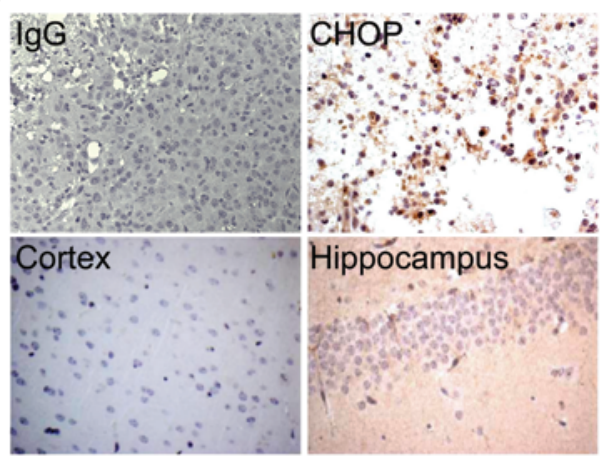

B

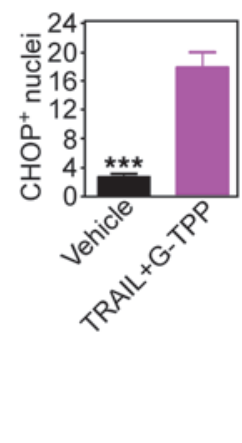

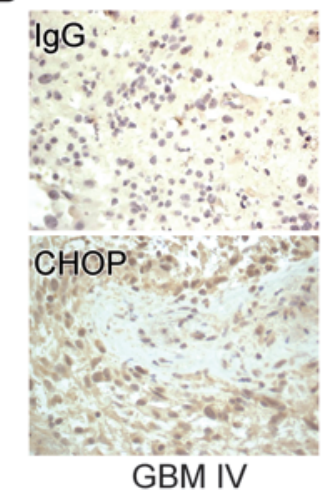

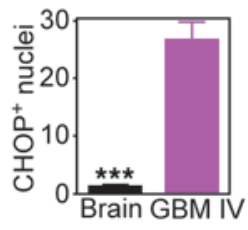

\section{Figure 10}

Activation of a mitochondrial UPR in cancer in vivo. (A) Brain sections from TRAIL+G-TPP-treated mice were stained with IgG or an antibody to CHOP (left), and immunoreactive nuclei were quantified (right). (B) Representative cases of WHO grade IV human glioblastoma or adjacent normal brain were stained with $\mathrm{lgG}$ or an antibody to $\mathrm{CHOP}$ (left), and immunoreactive nuclei were quantified (right). Mean $\pm \mathrm{SEM}$. ${ }^{* \star *} P<0.0001$. Original magnification, $\times 400$.

Progen), were unreactive. Primary FHAS were obtained from ScienCell Research Laboratories and maintained in culture as described above or, alternatively, transformed by expression of the SV40 oncogene.

Genetically engineered cell lines. To generate cell lines with stable shRNA knockdown of CypD or the IKK kinase, TGF- $\beta$-activated kinase (TAK1), CypD-directed (Dharmacon cat. no. RHS3979-9616542, RHS3979-9616543) or TAK1-directed (Dharmacon cat. no. RHS3979-9570052, RHS39799570053) shRNA in pLKO.1 lentivirus vector were cotransfected $(0.5 \mu \mathrm{g})$ in HEK293T cells in 6-well plates together with $0.33 \mu \mathrm{g}$ of pCMVdel8.2 and $0.2 \mu \mathrm{g}$ of pMDG (VSVG envelope glycoprotein) using Lipofectamine 2000 (Invitrogen). Retrovirus-containing supernatants were harvested 48 hours after transfection, followed by filtration through a $0.45-\mu \mathrm{m}$ pore size filter, and used to infect cultures of LN229 (CypD shRNA) or MCF-7 (TAK1 shRNA) cells in the presence of $4 \mu \mathrm{g} / \mathrm{ml}$ of polybrene. Stably transfected cells were selected in the presence of $1 \mu \mathrm{g} / \mathrm{ml}$ puromycin for at least 1 week, and independently established clones were selected for further experiments.

Antibodies. Antibodies to LC3 (Cell Signaling), CypD, COX-IV (1:1000; Calbiochem), cytochrome $c$ (1:1000; Clontech), Hsp70 (1:1000; Abcam), TRAP-1 (BD), Ki-67 (Zymed; Invitrogen), caspase-9 (1:250; CST), caspase-8 (1:250; CST), caspase-3 (1:100; CST), caspase-7 (1:500; CST), FLIP-L, long form (1:250; CST) FLIP-S, short form (1:250; CST), CrmA (SCBT), $\beta$-actin (1:2000; Sigma-Aldrich), mitochondrial superoxide dismutase-2 (SOD2; $5 \mu \mathrm{g} / \mathrm{ml}$; Sigma-Aldrich), survivin (NOVUS Biologicals), Bcl-2 (1:1000; CST), Bax (1:1000; CST), PUMA (1:1000; CST), Bcl-X (1:1000; CST), Bak (1:1000; CST), Bad (1:1000; CST), Bid (1:1000; CST), Mcl-1 (1:1000; CST), C/EBP/ $\beta$ (1:1000; CST), CHOP (1:1000; CST), TAK1 (1:1000; Santa Cruz Biotechnology Inc.), $\alpha$-glial fibrillary acidic protein (Dako), CD31 (BD Biosciences - Pharmingen) or factor VIII (Dako), or neuronal neurofilament proteins 70, 160, and 200 (all from Progen) were used.

Chemicals. The complete chemical synthesis, HPLC profile, and mass spectrometry of mitochondria-targeted small molecule Hsp90 antagonists Gamitrinibs has been reported previously (15). Gamitrinib ${ }^{\mathrm{TPP}}$ (G-TPP) was used in this study. Nonmitochondrial-permeable Hsp90 inhibitor 17-allylamino demethoxygeldanamycin (17-AAG) was obtained from LC-Laboratories. Recombinant TRAIL was obtained from Peprotech. Inhibitors of phagosome formation bafilomycin $\mathrm{A}(\mathrm{BF})$ or 3-methyladenine (3-MA) were obtained from Sigma-Aldrich.

Analysis of cell viability and autophagy. The various cell types were seeded in triplicate onto 96 -well plates at $2 \times 10^{3}$ cells/well, treated with vehicle, G-TPP, or nontargeted 17-AAG $(0-20 \mu \mathrm{M})$ for up to 24 hours, and quantified for metabolic activity by a 3(4,5-dimethyl-thyazoyl-2-yl)2,5 diphenyltetrazolium bromide (MTT) colorimetric assay with absorbance at $405 \mathrm{~nm}$, as described (46). For determination of apoptosis, control or treated tumor cell types $\left(1 \times 10^{6}\right)$ were labeled for annexin $V$ and propidium iodide (PI) (BD Biosciences) and analyzed by multiparametric flow cytometry $(\mathrm{BD})$, as described $(13,15)$. Mitochondrial or cytosolic extracts were prepared as described previously (13) from treated glioblastoma cell types and analyzed for release of cytochrome $c$, redistribution of proapoptotic Bax, or proteolytic processing of upstream or effector caspases by Western blotting. For G-TPP-TRAIL combination studies, tumor cell types were simultaneously incubated with suboptimal concentrations of G-TPP at $5 \mu \mathrm{M}$ and TRAIL depending on the cell type at $100 \mathrm{ng} / \mathrm{ml}$ (U87), $20 \mathrm{ng} / \mathrm{ml}$ (U251), $40 \mathrm{ng} / \mathrm{ml}$ (PC3, MCF-7, FHAS), or $200 \mathrm{ng} / \mathrm{ml}$ (LN229), and analyzed after 16 hours for cell viability by MTT, DNA content by PI staining, and flow cytometry or annexin V/PI staining and multiparametric flow cytometry. Changes in protein expression under the various combination regimens were determined by immunoblotting.

For autophagy, glioblastoma cells were transfected with an LC3-GFP cDNA by FuGENE HD (Roche), treated with vehicle, nontargeted 17-AAG, or G-TPP, and analyzed by fluorescence microscopy. A cell was scored as autophagic when exhibiting a punctate GFP labeling with more than 10 LC3-GFP dots/cell. An average of 200 cells was counted in 4-6 independent fields per condition. In some experiments, G-TPP-treated cells were incubated with pharmacologic inhibitors of autophagy, BF, or 3-MA, and analyzed after 16 hours for modulation of cell viability by MTT.

Mitochondrial membrane potential. To quantify changes in mitochondrial membrane potential, U251 cells were plated on optical-grade $35-\mathrm{mm}$ glass-bottom tissue culture dishes labeled with $0.1 \mu \mathrm{M}$ of the mitochondrial membrane potential-sensitive fluorescent dye, tetramethylrhodamine methyl ester (TMRM), as described (13). Cells were treated with TRAIL or G-TPP, alone or in combination, and imaged continuously on a Nikon TE2000-E2 with a Perfect Focus System inverted microscope using a CSU10B Spinning Disk Confocal System. Images were acquired by timelapse videomicroscopy on a Rolera Mgi EMCCD camera in an environmental chamber $(20 / 20$ Technology) using a $\times 60$ objective and quantified for real-time kinetics of changes in mitochondrial membrane potential.

Analysis of mitochondrial protein folding. LN229 cells were treated with vehicle or G-TPP $(5 \mu \mathrm{M})$ for 16 hours, harvested, and mixed with increasing concentrations ( $0 \%-0.5 \%)$ of NP40. Detergent-insoluble mitochondrial 
extracts under the various conditions tested were separated by SDS gel electrophoresis, and protein bands were visualized by silver staining (9).

$E M$. Subconfluent monolayers of LN229 cells were incubated with PBS, $\mathrm{pH} 7.2$, or G-TPP or nontargeted 17-AAG $(5-10 \mu \mathrm{M})$ for 16 hours at $37^{\circ} \mathrm{C}$. Cells were washed briefly in $0.1 \mathrm{M} \mathrm{PBS}$, pH 7.4, fixed in buffered $2.5 \%$ glutaraldehyde (GA) with or without $4 \%$ formaldehyde (FA) or for 30 minutes at $22^{\circ} \mathrm{C}$, post-fixed in $1 \%$ osmium tetroxide, and processed by standard methods for epoxy embedding. In some experiments, cells were fixed in buffered $3 \% \mathrm{FA}$ with $0.1 \% \mathrm{GA}$ for 25 minutes at $22^{\circ} \mathrm{C}$, washed, quenched with $\mathrm{NH}_{4} \mathrm{Cl}$, and dehydrated for embedding in LR White resin. Ultrathin sections on nickel grids were treated for heat-induced antigen retrieval and blocked with buffered $1 \%$ BSA, as described in published protocols (47). Samples were incubated with an antibody to COX IV, followed by a colloidal goldconjugated (12 nm) secondary antibody of appropriate specificity (Jackson ImmunoResearch). Grids were briefly post-fixed with $2 \% \mathrm{GA}$, washed, air dried, and then exposed to osmium tetroxide vapors for 20 minutes. Ultrathin sections were stained with uranyl acetate and lead citrate before examination in a Philips CM10 transmission electron microscope.

Promoter activity. Tumor cell types were transfected with NF-кB (48), p53, or FLIP luciferase promoter construct (pGL3-FLIP1500; Addgene \#16016) using FuGENE HD. After 24 hours at $37^{\circ} \mathrm{C}$, cells were stimulated with G-TPP or 17-AAG $(0-10 \mu \mathrm{M})$ for 6 hours, or alternatively, exposed to the mitochondrial uncoupler carboxy cyanide 3-chlorophenyl hydrazone (CCCP) $(0-15 \mu \mathrm{M})$ or the broad-spectrum apoptotic stimulus STS $(1-2 \mu \mathrm{M})$, harvested, and analyzed for $\beta$-galactosidase-normalized luciferase activity in a luminometer, as described (48). In some experiments, $\beta$-galactosidase-normalized NF- $\kappa B$ promoter activity was examined after cell stimulation with TNF- $\alpha$, as described (48). Microarray data quantifying changes in gene expression in untreated or G-TPP-treated U251 cells were deposited in the GEO database (GSE26313).

Transfections. Glioblastoma cell types were transfected with nontargeting or CHOP-directed SMARTpool siRNA (Dharmacon cat. no. L-004819-000005) using Oligofectamine 2000, characterized for protein knockdown by immunoblotting, and processed for further studies. In some experiments, glioblastoma cell types were transfected with control pcDNA3 or plasmid encoding WT CHOP, a CHOP deletion mutant lacking the leucine zipper motif (CHOP- $\Delta$ Leu) (23), an IкB $\alpha$ "super-repressor" mutant (48), C/EBP $\beta$, the caspase-8 inhibitor, CrmA, FLIP-L (long form), or FLIP-S (short form), by lipofectamine. Cells were examined for recombinant protein expression by immunoblotting, left untreated, or incubated with G-TPP with or without TRAIL, and analyzed for changes in NF-אB promoter activity with or without TNF- $\alpha$, or, alternatively, for cell viability by MTT or hypodiploid DNA content (sub-G1 cell fraction) by PI staining and flow cytometry. Alternatively, glioblastoma cells were transfected with nontargeting siRNA, TRAP-1- (13), or caspase-8-directed siRNA (Dharmacon cat. no. L-003466-00-0005), confirmed for protein knockdown by immunoblotting, and analyzed for DNA content and flow cytometry.

In vivo glioblastoma model. All experiments involving animals were approved by the Institutional Animal Care and Use Committee at the University of Massachusetts Medical School. U87 glioblastoma cells stably transfected with a luciferase expression plasmid (U87-Luc) were suspended in sterile PBS, pH 7.2, and stereotactically implanted $\left(1 \times 10^{5}\right)$ in the right cerebral striatum of immunocompromised nude mice (Charles River Laboratories). Animals with established tumors were randomized in 4 groups ( 4 animals/group) and started on sterile vehicle (cremophor), TRAIL alone, G-TPP alone, or the combination of TRAIL plus G-TPP. In all animal groups, TRAIL was injected stereotactically in the right cerebral striatum ( $2 \mathrm{ng}$ on days 7 and 10 after implantation), and G-TPP was given systemically $(10 \mathrm{mg} / \mathrm{kg}$ as daily i.p. injections on days $6,7,9$, and 10 after implantation). Treatment was suspended on day 10 after tumor implantation, and tumor growth was assessed weekly by bioluminescence imaging on a Xenogen In Vivo Imaging System after i.p injection of $110 \mathrm{mg} / \mathrm{kg}$ D-luciferin. In some experiments, nude mice carrying established U87-Luc intracranial glioblastomas were treated with systemic G-TPP monotherapy at $20 \mathrm{mg} / \mathrm{kg}$ as daily i.p. injections and monitored for tumor growth by bioluminescence imaging. Animal survival was calculated per group. At the end of the experiment, brains from control or treated animals were harvested and analyzed by histology.

Histology. Brain specimens from the various animal groups were stained with $\mathrm{H} \& \mathrm{E}$ or with an antibody to $\mathrm{CHOP}$, as described (15). For in situ determination of cell proliferation or apoptosis, brain sections were analyzed with an antibody to Ki-67, cleaved caspase-3, or TUNEL (Roche). Images were collected on an Olympus microscope with on-line charge-coupled device camera. In some experiments, patient-derived primary glioblastoma samples were stained with an antibody to CHOP or nonbinding IgG by immunohistochemistry, as described $(13,15)$. Immunoreactive cells were scored semiquantitatively for staining intensity as 0 , negative; 1 , low; 2 , medium; 3 , high; and percentage of $\mathrm{CHOP}$ expression in the cell population as 0 , no expression; 1 , less than $1 \% ; 2,1 \%-9 \% ; 3,10 \%-50 \%$; and 4 , more than $50 \%$, as described (49).

Statistics. Data were analyzed by 2 -sided unpaired $t$ tests using a GraphPad software package (Prism 4.0) for Windows. For experiments of luciferase promoter expression or MTT, data are expressed as mean \pm SD or mean \pm SEM of replicates of a representative experiment out of at least 2 independent determinations. $P \leq 0.05$ was considered statistically significant.

\section{Acknowledgments}

We thank Eric Baehrecke and Claire-Marie Sauvageot for reagents, and Kathryn Chase and Neil Aronin for stereotactical frames. This work was supported by NIH grants CA140043, CA78810, HL54131, and CA118005 (to D.C. Altieri) and Deutsche Forschungsgemeinschaft grant Si 1546/1-1 (to M.D. Siegelin).

Received for publication December 5, 2010, and accepted in revised form January 5, 2011.

Address correspondence to: Dario C. Altieri, The Wistar Institute Cancer Center, 3601 Spruce Street, Philadelphia, Pennsylvania 19104, USA. Phone: 215.495.6970; Fax: 215.495.6971; E-mail: daltieri@wistar.org.

Markus D. Siegelin's present address is: Department of Pathology and Cell Biology, Columbia University Medical Center, New York, New York, USA.
1. Butow RA, Avadhani NG. Mitochondrial signaling: the retrograde response. Mol Cell. 2004;14(1):1-15.

2. Ron D, Walter P. Signal integration in the endoplasmic reticulum unfolded protein response. Nat Rev Mol Cell Biol. 2007;8(7):519-529.

3. Ma Y, Hendershot LM. The role of the unfolded protein response in tumour development: friend or foe? Nat Rev Cancer. 2004;4(12):966-977.

4. Kaufman RJ. Orchestrating the unfolded pro- tein response in health and disease. J Clin Invest. 2002;110(10):1389-1398.

5. Amuthan G, Biswas G, Zhang SY, Klein-Szanto A, Vijayasarathy C, Avadhani NG. Mitochondria-tonucleus stress signaling induces phenotypic changes, tumor progression and cell invasion. $E M B O J$. 2001;20(8):1910-1920.

6. Kim I, Xu W, Reed JC. Cell death and endoplasmic reticulum stress: disease relevance and therapeutic opportunities. Nat Rev Drug Discov. 2008;7(12):1013-1030.

7. Hetz C, Glimcher LH. Fine-tuning of the unfolded protein response: Assembling the IRE1alpha interactome. Mol Cell. 2009;35(5):551-561.

8. Martinus RD, et al. Selective induction of mitochondrial chaperones in response to loss of the mitochondrial genome. Eur J Biochem. 1996; 240(1):98-103. 
9. Moisoi N, et al. Mitochondrial dysfunction triggered by loss of HtrA2 results in the activation of a brain-specific transcriptional stress response. Cell Death Differ. 2009;16(3):449-464.

10. Zhao Q, Wang J, Levichkin IV, Stasinopoulos S, Ryan MT, Hoogenraad NJ. A mitochondrial specific stress response in mammalian cells. EMBOJ. 2002;21(17):4411-4419.

11. Whitesell L, Lindquist SL. HSP90 and the chaperoning of cancer. Nat Rev Cancer. 2005;5(10):761-772.

12. Trepel J, Mollapour M, Giaccone G, Neckers L. Targeting the dynamic HSP90 complex in cancer. Nat Rev Cancer. 2010;10(8):537-549.

13. Kang BH, Plescia J, Dohi T, Rosa J, Doxsey SJ, Altieri DC. Regulation of tumor cell mitochondrial homeostasis by an organelle-specific Hsp90 chaperone network. Cell. 2007;131(2):257-270.

14. Green DR, Kroemer G. The pathophysiology of mitochondrial cell death. Science. 2004; 305(5684):626-629.

15. Kang BH, et al. Combinatorial drug design targeting multiple cancer signaling networks controlled by mitochondrial Hsp90. J Clin Invest. 2009; 119(3):454-464.

16. Isaacs JS, Xu W, Neckers L. Heat shock protein 90 as a molecular target for cancer therapeutics. Cancer Cell. 2003;3(3):213-217.

17. Armstrong JS. Mitochondrial medicine: pharmacological targeting of mitochondria in disease. BrJ Pharmacol. 2007;151(8):1154-1165.

18. Purow B, Schiff D. Advances in the genetics of glioblastoma: are we reaching critical mass? Nat Rev Neurol. 2009;5(8):419-426.

19. Levine B, Kroemer G. Autophagy in the pathogenesis of disease. Cell. 2008;132(1):27-42.

20. Mathew R, et al. Autophagy suppresses tumorigenesis through elimination of p62. Cell. 2009; 137(6):1062-1075.

21. Chaudhuri TK, Farr GW, Fenton WA, Rospert S, Horwich AL. GroEL/GroES-mediated folding of a protein too large to be encapsulated. Cell. 2001; 107(2):235-246.

22. Baud V, Karin M. Is NF-[kappa]B a good target for cancer therapy? Hopes and pitfalls. Nat Rev Drug Discov. 2009;8(1):33-40.

23. Du S, et al. Suppression of NF-kappaB by cyclo- sporin a and tacrolimus (FK506) via induction of the C/EBP family: implication for unfolded protein response. J Immunol. 2009;182(11):7201-7211.

24. Ashkenazi A. Directing cancer cells to self-destruct with pro-apoptotic receptor agonists. Nat Rev Drug Discov. 2008;7(12):1001-1012.

25. Travers KJ, Patil CK, Wodicka L, Lockhart DJ, Weissman JS, Walter P. Functional and genomic analyses reveal an essential coordination between the unfolded protein response and ER-associated degradation. Cell. 2000;101(3):249-258.

26. Szabadkai G, et al. Chaperone-mediated coupling of endoplasmic reticulum and mitochondrial $\mathrm{Ca} 2+$ channels. J Cell Biol. 2006;175(6):901-911.

27. Eletto D, Dersh D, Argon Y. GRP94 in ER quality control and stress responses. Semin Cell Dev Biol. 2010; 21(5):479-485.

28. Ischiropoulos H, Beckman JS. Oxidative stress and nitration in neurodegeneration: cause, effect, or association? J Clin Invest. 2003;111(2):163-169.

29. Young JC, Hoogenraad NJ, Hartl FU. Molecular chaperones Hsp90 and Hsp70 deliver preproteins to the mitochondrial import receptor Tom70. Cell. 2003;112(1):41-50.

30. Haynes CM, Ron D. The mitochondrial UPR - protecting organelle protein homeostasis. JCell Sci. 2010; 123(pt 22):3849-3855.

31. Haynes CM, Yang Y, Blais SP, Neubert TA, Ron D. The matrix peptide exporter HAF-1 signals a mitochondrial UPR by activating the transcription factor ZC376.7 in C. elegans. Mol Cell. 2010;37(4):529-540.

32. Hardie DG. AMP-activated/SNF1 protein kinases: conserved guardians of cellular energy. Nat Rev Mol Cell Biol. 2007;8(10):774-785.

33. Hayashi T, Su TP. Sigma-1 receptor chaperones at the ER-mitochondrion interface regulate $\mathrm{Ca}(2+)$ signaling and cell survival. Cell. 2007;131(3):596-610.

34. Giorgi C, De Stefani D, Bononi A, Rizzuto R, Pinton P. Structural and functional link between the mitochondrial network and the endoplasmic reticulum. Int J Biochem Cell Biol. 2009;41(10):1817-1827.

35. Moreau K, Luo S, Rubinsztein DC. Cytoprotective roles for autophagy. Curr Opin Cell Biol. 2010;22(2):206-211.

36. Bernales S, McDonald KL, Walter P. Autophagy counterbalances endoplasmic reticulum expan- sion during the unfolded protein response. PLoS Biol. 2006;4(12):e423.

37. Ogata M, et al. Autophagy is activated for cell survival after endoplasmic reticulum stress. Mol Cell Biol. 2006;26(24):9220-9231.

38. Chen H, Chan DC. Mitochondrial dynamics-fusion, fission, movement, and mitophagy--in neurodegenerative diseases. Hum Mol Genet. 2009; 18(R2):R169-R176.

39. Chu CT. A pivotal role for PINK1 and autophagy in mitochondrial quality control: implications for Parkinson disease. Hum Mol Genet. 2010; 19(R1):R28-R37.

40. Harama D, et al. A subcytotoxic dose of subtilase cytotoxin prevents lipopolysaccharide-induced inflammatory responses, depending on its capacity to induce the unfolded protein response. J Immunol. 2009;183(2):1368-1374.

41. Green DR, Kroemer G. Pharmacological manipulation of cell death: clinical applications in sight? J Clin Invest. 2005;115(10):2610-2617.

42. So AY, de la Fuente E, Walter P, Shuman M, Bernales $S$. The unfolded protein response during prostate cancer development. Cancer Metastasis Rev. 2009;28(1-2):219-223.

43. Mazure NM, Pouyssegur J. Hypoxia-induced autophagy: cell death or cell survival? Curr Opin Cell Biol. 2010;22(2):177-180.

44. Fulda S, Galluzzi L, Kroemer G. Targeting mitochondria for cancer therapy. Nat Rev Drug Discov. 2010;9(6):447-464.

45. Fesik SW. Promoting apoptosis as a strategy for cancer drug discovery. Nat Rev Cancer. 2005;5(11):876-885.

46. Plescia J, et al. Rational design of shepherdin, a novel anticancer agent. Cancer Cell. 2005;7(5):457-468.

47. Yamashita S. The post-embedding method for immunoelectron microscopy of mammalian tissues: a standardized procedure based on heatinduced antigen retrieval. Methods Mol Biol. 2010; 657:237-248.

48. Mehrotra S, Languino LR, Raskett CM, Mercurio AM, Dohi T, Altieri DC. IAP regulation of metastasis. Cancer Cell. 2010;17(1):53-64.

49. Siegelin MD, Habel A, Gaiser T. 17-AAG sensitized malignant glioma cells to death-receptor mediated apoptosis. Neurobiol Dis. 2009;33(2):243-249. 